\title{
Myeloperoxidase G-463A polymorphism and lung cancer: A HuGE Genetic Susceptibility to Environmental Carcinogens pooled analysis
}

Emanuela Taioli, $\mathrm{MD}, \mathrm{PhD}^{1}$, Simone Benhamou, $\mathrm{PhD}^{2}$, Christine Bouchardy, $\mathrm{MD}, \mathrm{MPH} \mathrm{H}^{3}$, Ingolf Cascorbi, $\mathrm{MD}, \mathrm{PhD} \mathrm{D}^{4}$, Nohelia Cajas-Salazar, $P h D^{5}$, Heike Dally, $P h D^{6}$, Kwun M. Fong, $M D, P h D^{7}$, Jill E. Larsen, BSc (Hons) ${ }^{7}$, Loic Le Marchand, $M D, P h D^{8}$, Stephanie J. London, $M D F, P h D^{9}$, Angela Risch, MA, DPhil ${ }^{6}$, Margaret R. Spitz, MD, MPH ${ }^{10}$, Isabelle Stucker, $P h D^{11}$, Brian Weinshenker, $M D^{12}$, Xifeng $W u, M D, P h D^{10}$, and Ping Yang, $\mathrm{MD}, \mathrm{PhD}^{12}$

Myeloperoxidase is a phase I metabolic enzyme that converts the metabolites of benzo[a]pyrene from tobacco
smoke into highly reactive epoxides. A polymorphism in the promoter region of myeloperoxidase (463G $\rightarrow$ A) has
been found to be inversely associated with lung cancer; differences in the association with age and gender have
been suggested. We conducted a pooled analysis of individual data from 10 studies (3688 cases and 3874
controls) from the Genetic Susceptibility to Environmental Carcinogens database. The odds ratio for lung cancer
was 0.88 (95\% confidence interval: 0.80-0.97) for the AG variant of myeloperoxidase G-463A polymorphism, and
0.71 ( $95 \%$ confidence interval: $0.57-0.88$ ) for the AA variant after adjusting for smoking, age, gender, and
ethnicity. The inverse association between lung cancer and myeloperoxidase G-463A polymorphism was equally
found in males and females (odds ratio for the AA genotype 0.73 [95\% confidence interval: 0.56-0.96] and 0.67
[95\% confidence interval: 0.46-0.98], respectively), without differences in the association according to age in the
two genders. The myeloperoxidase G-463A polymorphism was significantly protective in "ever" smokers but not in
"never" smokers. Myeloperoxidase is a key enzyme in tobacco-induced carcinogenesis. Genet Med 2007:9(2):67-73.

Key Words: Epidemiology, cooperative studies, metabolic gene polymorphisms, smoking

Myeloperoxidase (MPO) is the product of a single gene of approximately $11 \mathrm{~kb}$ composed of 11 introns and 12 exons, and located in the long arm of chromosome 17, segment q12-24. ${ }^{1}$ The MPO protein is a tetramer composed of two $59-\mathrm{kD}$ subunits, joined together by a single disulfide bridge containing a heme prosthetic group, ${ }^{2}$ and two $12-\mathrm{kD}$ subunits. ${ }^{3} \mathrm{MPO}$ is synthesized as a large precursor polypeptide chain with a molecular weight of approximately $80 \mathrm{kD}$, is processed into the

From the ${ }^{1}$ University of Pittsburgh, Cancer Institute, Pittsburgh, Pensylvania; ${ }^{2}$ INSERM U794, Evry, France; ${ }^{3}$ Geneva Cancer Registry, Geneva, Switzerland; Institute of Pharmacology, University Hospital Schleswig-Holstein, Kiel, Germany; ${ }^{5}$ Department of Preventive Medicine and Community Health, The University of Texas Medical Branch, Galveston, Texas; ${ }^{6}$ Deutsches Krebsforschungszentrum, Abteilung Toxikologie und Krebsrisikofaktoren, Heidelberg, Germany; ${ }^{7}$ Department of Thoracic Medicine, The Prince Charles Hospital, Brisbane, Australia, ${ }^{8}$ Cancer Research Center of Hawaii, University of Hawaii, Honolulu, Hawaii; ${ }^{9}$ National Institute of Environmental Health Sciences, Research Triangle Park, North Carolina; ${ }^{10}$ Department of Epidemiology, University of Texas M.D. Anderson Cancer Center, Houston, Texas; ${ }^{11}$ Epidemiologic and Statistical Research on Environment and Health, INSERM U170, Villejuif, France; and ${ }^{12}$ Mayo Clinic Cancer Center, Mayo Clinic College of Medicine, Rochester, Minnesota.

Emanuela Taioli, MD, PhD, University of Pittsburgh Cancer Institute, 5150 Centre Ave, Pittsburgh, PA 15232.

The authors declare no conflict of interest.

Submitted for publication July 24, 2006.

Accepted for publication November 12, 2006.

DOI: 10.1097/GIM.0b013e31803068b1 enzymatically inactive apopro-MPO in the prelysosomal and lysosomal structures, ${ }^{4}$ and is then bound with the calciumbinding proteins calreticulin and calnexin in the endoplasmic reticulum. The insertion of a heme group converts the inactive form into the enzymatically active compound ${ }^{1}$ found in large amounts in the azurophilic granules of polymorphonuclear neutrophils and in monocytes and macrophages. ${ }^{5}$ Three different MPO forms have been described, ${ }^{6}$ with similar spectral properties and amino acid composition but different substrate specificity and activity.

\section{GENE FUNCTION}

MPO is a phase I metabolic enzyme that converts lipophilic carcinogens into hydrophilic forms and activates several components of tobacco smoke, such as polycyclic aromatic amines and heterocyclic amines. MPO is also a component of the microbicidal network of polymorphonuclear leukocytes, ${ }^{3,7}$ which produces hypochlorous acid and other reactive oxygen species during the phagocytosis process. ${ }^{8}$ These oxidants can react with biological molecules to give secondary free radicals and have been associated with lipid peroxidation, ${ }^{9}$ DNA damage, single or double-strand breaks, denaturation or bases substitutions, DNA cross-linking, ${ }^{8}$ alterations in signal transduction pathways, ${ }^{10}$ and cell growth. ${ }^{11}$ 
Some $25 \%$ to $40 \%$ of the $\mathrm{H}_{2} \mathrm{O}_{2}$ produced by activated neutrophils may be converted to hypochlorous acid through reactions involving MPO, ${ }^{1,3,12,13}$ with subsequent extensive DNA base modification, including formation of chlorinated bases. ${ }^{14}$ The process is enhanced by the presence of tertiary amines, such as nicotine. ${ }^{15}$

\section{GENE VARIANTS}

Several single nucleotide polymorphisms have been identified in the MPO locus. The first reported polymorphism ${ }^{16}$ was a $\mathrm{C} \rightarrow \mathrm{T}$ substitution at nucleotide 8089 in exon 10; it causes hereditary MPO deficiency and affects 1 in 2000 to 4000 individuals. At the amino acid level, tryptophan $(T G G)$ replaces arginine (CGG) at codon $569^{17}$ and results in a form of apopro$\mathrm{MPO}$ that does not undergo posttranslational processing to enzymatically active MPO species. ${ }^{18}$ Another polymorphism associated with MPO deficiency was identified in exon 4, corresponding to a $-173 T y r \rightarrow C y s$ change. ${ }^{19}$ The consequence is a modified MPO protein that remains in the endoplasmic reticulum bound to calreticulin and calnexin and then gets degraded. A further cause of MPO deficiency is a $T \rightarrow C$ transition causing the nonconservative replacement $251 \mathrm{Met} \rightarrow \mathrm{Th} r$ in the C-terminal region of the light chain and a 14-base pair deletion within exon $9 .{ }^{20}$

A polymorphism located in the promoter region, 463 base pairs upstream of the MPO gene, decreases MPO gene expression by destroying a binding site for the SP1 transcription factor. $^{21}$ The single $G$ to $A$ base substitution is associated with reduced MPO mRNA expression and decreased MPO enzyme levels, ${ }^{20}$ whereas the $G$ allele is associated with increased MPO production. ${ }^{1}$ The base change leads to the loss of the SP1 transcription binding site in an Alu hormone-responsive element; ${ }^{21}$ these short DNA elements contain binding sites for key transcription factors, including retinoic acid receptor, estrogen receptor, PPARgamma, thyroid hormone receptor, and SP1 transcription factor. ${ }^{22}$ MPO activity in homozygous variant individuals (MPO-463AA) was reported to be more than three times lower than in homozygous wild-type subjects (MPO-463GG).23 The MPO G/G genotype has been associated with acute promyelocytic leukemia, ${ }^{24}$ coronary artery disease ${ }^{25}$ and aerodigestive tract cancer, ${ }^{26}$ early-onset multiple sclerosis, ${ }^{27}$ increased incidence of Alzheimer disease, ${ }^{28}$ and higher risk of periodontal disease in women, but not in men. ${ }^{29}$ A recent meta-analysis ${ }^{30}$ indicates that the variant alleles (GA plus AA) are associated with decreased risk of lung cancer in Japanese, and to a less extent in Caucasians.

\section{DATA COLLECTION}

The Genetic Susceptibility to Environmental Carcinogens (GSEC) database (http://www.upci.upmc.edu/research/ccps/ ccontrol/index.html) is a collaborative project that gathers information from both published and unpublished case-control studies on metabolic gene polymorphisms and cancer. ${ }^{31} \mathrm{~A}$ questionnaire was provided to each investigator at the time of enrollment in the study, collecting information on the study design, selection and source of controls, laboratory methods used for genotyping, source of DNA for genotype analysis, and response rates for both cases and controls. Studies reporting information on MPO G-463A and lung cancer were selected from the GSEC database. The investigators of the published studies for which data were not available through the GSEC project were then contacted and asked to provide their data for this specific pooled analysis. Of the 15 studies available from Medline, we obtained individual data from 10 studies for a total of 3688 cases and 3874 controls (Table 1).

\section{Statistical analysis}

The frequency of the MPO G-463A polymorphism in cases and controls was calculated, and the departure of MPO G-463A frequencies from expectation under Hardy-Weinberg (HW) equilibrium was tested among controls. ${ }^{32}$ Study-specific crude odds ratios (ORs) and 95\% confidence intervals (CIs) for lung cancer were calculated. Summary ORs were calculated for all the studies combined; the Egger test was performed to assess publication bias $^{33}$ on the overall dataset and according to ethnicity when more than two studies were available (Caucasians, Asians, African Americans, and other ethnic groups). Funnel plots were used for a graphic representation of publication bias.

The Q statistic was used to test the hypothesis of homogeneity among all the studies, with $P$ values less than .05 indicating the presence of heterogeneity among studies. ${ }^{34}$ Adjusted ORs were then calculated using multivariate logistic regression models. Data were adjusted for ethnicity (Caucasians, Asians, African Americans, and others), age (as continuous variable and categorized as $\leq 50$ and $>50$ years), study number, gender (male/female), and smoking status (never/ever).

The Armitage test for trend was used to assess the change in risk with smoking dose in subjects carrying the MPO polymorphism. All of the analyses were repeated excluding the studies in which the control frequencies were not in HW equilibrium.

\section{GENOTYPE FREQUENCY}

The frequency of the variant genotype AA of the MPO G-463A polymorphism was reported in a meta-analysis to be $5.4 \%$ in Caucasians, ${ }^{30}$ slightly higher that what is reported in the GSEC database $(4.6 \%, 95 \%$ CI $4.1-5.1)$, and $1.9 \%$ in Asians. The GSEC database shows higher frequencies of the AA variant in Asian populations (5.0\%, 95\% CI 4.3-6.1).

The frequency of the MPO G-463A polymorphism was 9.5\% among the African American control populations included in the GSEC study and 5.2\% in mixed populations (Table 2).

The distribution of the MPO G-463A polymorphism in the controls $5,8,26,35,36,38,40,41,46,50,51,52$ significantly departed from HW equilibrium in three of the studies included in the pooled analysis. The diverse ethnicity included in the study was the 
Table 1

Studies included in the pooled analysis on myeloperoxidase and lung cancer: Genetic Susceptibility to Environmental Carcinogens dataset

\begin{tabular}{|c|c|c|c|c|c|c|}
\hline Study reference no. & MPO & Cases & Controls & OR $(95 \% \mathrm{CI})$ & Ethnicity & Source \\
\hline \multirow[t]{3}{*}{5} & GG & $135(55.6)$ & $140(57.1)$ & $1.0(\mathrm{ref})$ & Caucasian & Hospital \\
\hline & GA & $98(40.3)$ & $93(38.0)$ & $1.09(0.76-1.58)$ & & \\
\hline & $\mathrm{AA}$ & $10(4.1)$ & $12(4.9)$ & $0.86(0.35-2.14)$ & & \\
\hline \multirow[t]{3}{*}{26} & GG & $141(71.9)$ & $185(61.1)^{a}$ & 1.0 (ref) & Caucasian & Healthy \\
\hline & GA & $49(25.0)$ & $112(37.0)$ & $0.57(0.37-0.90)$ & & \\
\hline & $\mathrm{AA}$ & $6(1.0)$ & $6(2.0)$ & $1.31(0.41-4.15)$ & & \\
\hline \multirow[t]{3}{*}{$8,35,36$} & GG & $235(62.7)$ & $202(53.4)$ & 1.0 (ref) & Caucasian & Healthy \\
\hline & GA & $126(33.6)$ & $157(41.5)$ & $0.69(0.51-0.94)$ & & \\
\hline & $\mathrm{AA}$ & $14(3.7)$ & $19(5.0)$ & $0.63(0.29-1.36)$ & & \\
\hline \multirow[t]{3}{*}{38} & GG & $630(65.5)$ & $372(66.2)$ & 1.0 (ref) & Caucasian & Hospital \\
\hline & GA & $294(30.6)$ & $163(29.0)$ & $1.07(0.87-1.31)$ & & \\
\hline & $\mathrm{AA}$ & $38(4.0)$ & $27(4.8)$ & $0.83(0.52-1.33)$ & & \\
\hline \multirow[t]{3}{*}{40} & GG & $190(56.2)$ & $398(56.9)^{a}$ & 1.0 (ref) & Caucasian, A-A & Healthy \\
\hline & GA & $132(39.1)$ & $243(34.7)$ & $1.14(0.85-1.53)$ & & \\
\hline & $\mathrm{AA}$ & $16(4.7)$ & $59(8.4)$ & $0.57(0.28-1.16)$ & & \\
\hline \multirow[t]{3}{*}{41} & GG & $234(72.5)$ & $294(67.3)^{a}$ & 1.0 (ref) & Caucasian, Asian, other & Population \\
\hline & GA & $77(23.8)$ & $116(26.5)$ & $0.83(0.58-1.19)$ & & \\
\hline & $\mathrm{AA}$ & $12(3.7)$ & $27(6.2)$ & $0.56(0.25-1.27)$ & & \\
\hline \multirow[t]{3}{*}{46} & GG & $76(45.5)$ & $71(48.6)$ & 1.0 (ref) & Caucasian, A-A, other & Healthy \\
\hline & GA & $79(45.5)$ & $68(46.6)$ & $1.09(0.69-1.70)$ & & \\
\hline & AA & $12(7.2)$ & $7(4.8)$ & $1.60(0.68-3.80)$ & & \\
\hline \multirow[t]{3}{*}{50} & GG & $98(65.3)$ & $96(55.8)$ & 1.0 (ref) & Caucasian & Hospital \\
\hline & GA & $42(28.0)$ & $63(36.3)$ & $0.65(0.39-1.09)$ & & \\
\hline & AA & $10(6.7)$ & $13(7.6)$ & $0.75(0.30-1.89)$ & & \\
\hline \multirow[t]{3}{*}{51} & GG & $193(62.7)$ & $181(59.0)$ & 1.0 (ref) & Caucasian, Asian, A-A, other & Hospital \\
\hline & GA & $106(34.4)$ & $111(36.2)$ & $0.90(0.64-1.25)$ & & \\
\hline & AA & $9(2.9)$ & $15(4.9)$ & $0.56(0.22-1.45)$ & & \\
\hline \multirow[t]{3}{*}{52} & GG & $381(60.9)$ & $383(61.4)$ & 1.0 (ref) & Caucasian & Hospital \\
\hline & GA & $205(32.7)$ & $209(33.5)$ & $0.99(0.78-1.25)$ & & \\
\hline & AA & $40(6.4)$ & $32(5.1)$ & $1.26(0.79-1.99)$ & & \\
\hline
\end{tabular}

MPO, myeloperoxidase; CI, confidence interval; (ref) OR, odds ratio; A-A, African American.

${ }^{a}$ Significant departure from Hardy-Weinberg equilibrium.

reason for departure in two of the studies, ${ }^{40,41}$ and the reason was not known in one study. ${ }^{26}$

\section{SUMMARY OF THE PUBLISHED DATA}

Before conducting the pooled analysis of individual data, we updated a previously published meta-analysis ${ }^{30}$ by including information on 15 published studies comprising 5239 cases and 5066 controls. The summary estimate for the association between the MPO variant (AG plus GG) and lung cancer was 0.91 (95\% CI: 0.84-0.99) using a random effect model because of the significant heterogeneity among studies ( $\mathrm{Q}$ test =
$31.477, P=.005)$. There was no evidence of publication bias $(P$ value was .1 for the Egger's test and .2 for the Begg test).

\section{POOLED ANALYSIS}

Overall, there was a significant inverse association between the MPO G-463A polymorphism and lung cancer, with a significant trend (Table 2). The OR was 0.88 (95\% CI: $0.80-0.97)$ for the AG variant of MPO G-463A polymorphism and 0.71 (95\% CI: 0.57-0.88) for the AA variant. There was some evidence of heterogeneity among studies for the association between the heterozygous variant MPO and lung cancer. A sen- 
Table 2

Association between myeloperoxidase polymorphism and lung cancer according to ethnicity, gender, and smoking status

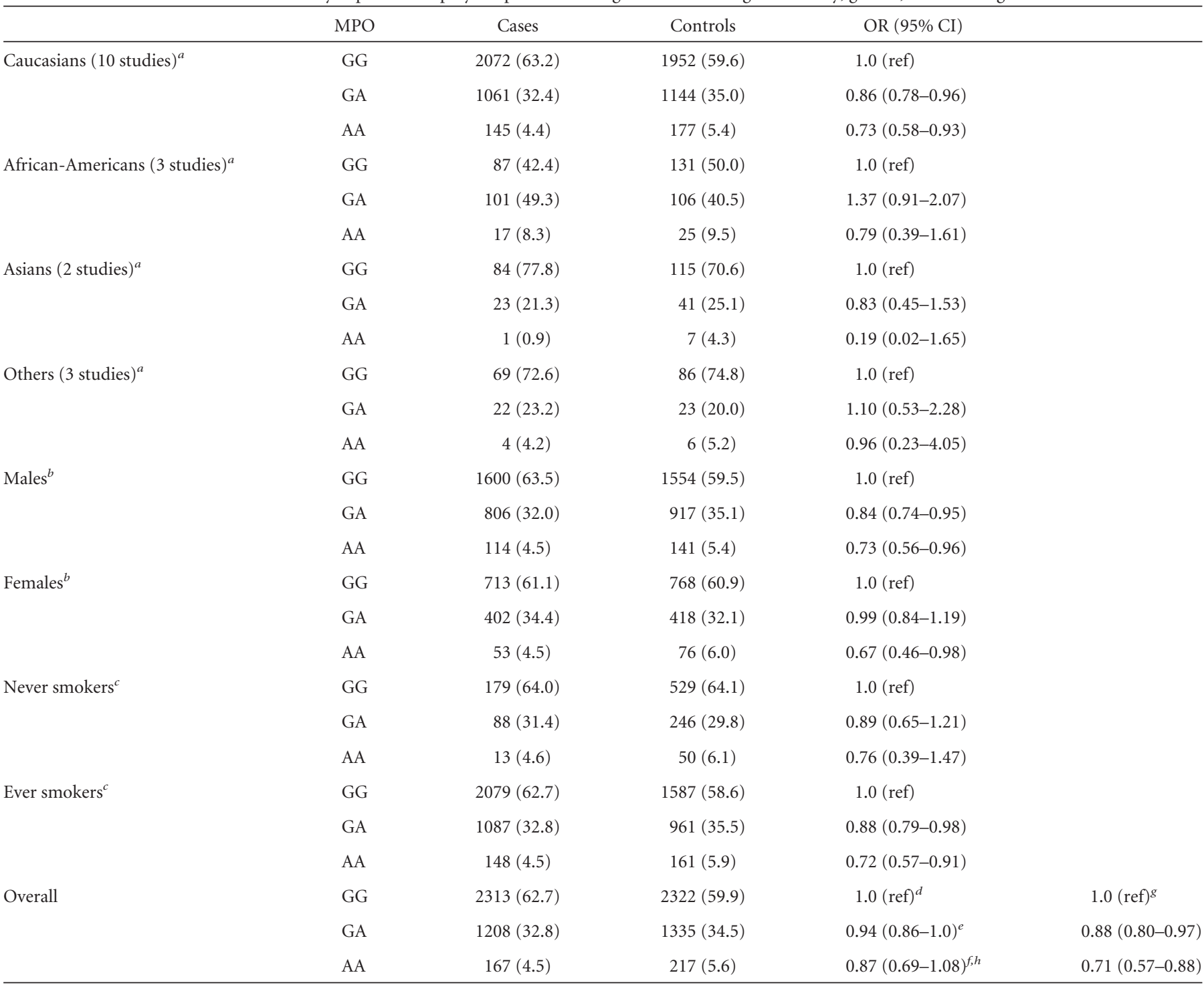

MPO, myeloperoxidase; (ref) OR, odds ratio; CI, confidence interval.

${ }^{a}$ Adjusted for smoking status (never/ever), age ( $\leq 50$ and $>50$ years), study number, and gender.

${ }^{b}$ Adjusted for smoking status (never/ever), age ( $\leq 50$ and $>50$ years), study number, and race.

${ }^{c}$ Adjusted for age ( $\leq 50$ and $>50$ years), study number, gender, and race.

${ }^{d}$ Random effect model.

${ }^{e} P$ value $Q$ test: .07, $P$ value Egger's test: .06.

${ }^{f} P$ value $Q$ test: .44, $P$ value Egger's test: .45.

${ }^{g}$ Adjusted for race, smoking status (never/ever), age ( $\leq 50$ and $>50$ years), study number, and gender.

${ }^{h}$ Test for trend: $8.2, P<.05$.

sitivity analysis suggested that the heterogeneity was deriving from the different ethnicities included in the studies. The stratified analysis according to ethnicity confirms the inverse association in Caucasians; the same trend, although nonsignificant, was observed in Asian and African-American populations. No association was observed in the group including mixed ethnicity. The inverse association between lung cancer and MPO G-463A polymorphism was equally found in males and females (OR for the AA genotype 0.73 [95\% CI: 0.56-0.96] and 0.67 [95\% CI: 0.46-0.98], respectively), without differences in the association according to age in the two genders (data not shown).
The MPO G-463A polymorphism was significantly inversely associated with lung cancer in ever smokers but not in never smokers; the OR for lung cancer with the AA homozygous MPO variant was 0.76 (95\% CI: $0.39-1.47$ ) in never smokers and 0.72 (95\% CI: 0.57-0.91) among ever smokers. However, a statistical interaction between smoking and the MPO polymorphism was not observed.

Among smokers, an increased risk of lung cancer was observed with increasing smoking dose in subjects carrying the GG wild-type genotype to a greater extent than for the GA and AA genotypes (Table 3). A significant trend for the decrease in 
Table 3

Association between smoking intensity and lung cancer according to myeloperoxidase genotype

\begin{tabular}{lccc}
\hline Smoking status & GG OR $(95 \%$ CI $)(\mathrm{n}$ cases/n controls $)$ & GA OR $(95 \%$ CI $)$ (n cases/n controls) & AA OR $(95 \%$ CI $)(\mathrm{n}$ cases/n controls $)$ \\
\hline Never smokers & $1.0($ ref $)(179 / 529)$ & $1.0($ ref $)(88 / 246)$ & $1.0($ ref $)(13 / 50)$ \\
$\leq 10$ cigarettes/d & $1.96(1.49-2.56)(148 / 235)$ & $2.02(1.41-2.87) 103 / 155$ & $1.54(0.62-3.83) 12 / 31$ \\
$11-20$ cigarettes/d & $3.15(2.52-3.93)(456 / 501)$ & $2.74(2.01-3.73) 245 / 296$ & $2.53(1.18-5.41) 38 / 59$ \\
$>20$ cigarettes/d & $3.98(3.19-4.96)(590 / 525)$ & $3.36(2.47-4.56) 321 / 337$ & $3.05(1.39-6.70)^{a} 36 / 47$ \\
$<50$ pack-y & $2.56(2.08-3.15)(1139 / 996)$ & $2.22(1.66-2.96)(604 / 620)$ & $2.14(1.04-4.38)^{b}(91 / 110)$ \\
$>50$ pack-y & $4.55(3.64-5.68)(880 / 544)$ & $4.10(3.01-5.58)(453 / 317)$ & $4.08(1.85-9.01)^{b}(56 / 44)$ \\
\hline
\end{tabular}

(ref) OR, odds ratio; CI, confidence interval.

Data are adjusted for age, study number, race, and gender.

Armitage test for trend across MPO genotype categories: ${ }^{a} P<.05 ;{ }^{b} P<.01$.

the association between smoking and lung cancer according to the MPO polymorphism was observed among smokers of 20 or more cigarettes per day. A similar phenomenon was observed when looking at pack-years as a measure of smoking history (Table 3). No changes in the association between occupational exposure and lung cancer according to the MPO G-463A polymorphism were observed (data not shown).

The association between the MPO G-463A polymorphism and lung cancer varied little according to histologic types (Table 4), with a slightly more protective effect present in carcinoma non otherwise specified than in other subtypes.

\section{DISCUSSION}

This pooled analysis of 10 published studies including 3688 cases and 3874 controls confirms the inverse relationship between lung cancer and the MPO G-463A polymorphism reported by a previous meta-analysis. ${ }^{30}$ In addition, we stratified the data according to ethnicity and observed that the association was present in Caucasians and was suggested in Asians but did not seem to be confirmed in populations of African or mixed descents, although the sample size of the latter group was limited in our study. Pooling of individual data has several advantages on a meta-analysis of published data, as described elsewhere. ${ }^{53}$ Because the pooled dataset includes additional information on several cofactors, it is possible to adjust the point estimates for potential confounding factors, to perform strati- fied analyses, and to study possible sources of heterogeneity. The present analysis assessed the pooled risk of lung cancer separately for both the MPO GA and the GG polymorphism, something that could not be done with a simple meta-analysis because of the restriction imposed by the availability of aggregate data from published studies. In addition, we stratified the data by ethnicity, gender, and age groups, another task that could not be fulfilled with a meta-analysis.

The MPO G-463A polymorphism displayed a significant inverse association with lung cancer in smokers, and in this group the effect was more marked with increasing smoking dose. A study in white smokers showed that DNA adduct levels in $M P O-A A$ individuals were twofold lower than in $M P O-A G$ subjects and fivefold lower than in MPO-GG subjects; MPO activity in homozygous variant individuals (MPO-463AA) was more than three times lower than in homozygous wild-type subjects (MPO-463GG).23

The association between MPO G-463A and lung cancer restricted to current smokers was suggested by a previous study. ${ }^{35}$ More recent studies reported an interaction with smoking and smoking dose, ${ }^{8,36-39}$ which was not confirmed by our analysis, although the association between smoking and lung cancer weakens in subjects carrying the heterozygous MPO variant, and even more in subjects carrying the homozygous variant form of the gene. It is likely that the reduced enzymatic activity of the MPO variant reduces the amount of

Table 4

Association between myeloperoxidase polymorphism and lung cancer according to histologic type

\begin{tabular}{lcrr}
\hline Histology & MPO GG N (\%) & MPO GA, AA N (\%) & OR $^{a}(95 \%$ CI $)$ \\
\hline Adenocarcinoma & $689(62.3)$ & $417(37.7)$ & $0.84(0.73-0.98)$ \\
Squamous cell carcinoma & $624(61.6)$ & $389(38.4)$ & $0.84(0.72-0.99)$ \\
Small cell & $356(65.9)$ & $184(34.1)$ & $0.75(0.61-0.92)$ \\
Large cell & $62(64.6)$ & $34(35.4)$ & $0.72(0.47-1.13)$ \\
Mixed & $201(58.1)$ & $145(41.9)$ & $1.04(0.82-1.31)$ \\
Carcinoma not specified & $110(70.5)$ & $46(29.5)$ & $0.63(0.44-0.91)$ \\
\hline
\end{tabular}

MPO, myeloperoxidase; OR, odds ratio; CI, confidence interval.

${ }^{a}$ OR of GA or AA versus GG adjusted for race, smoking status (never/ever), age ( $\leq 50$ and $>50$ years), study number, and gender. 
available carcinogens produced as by-products of the metabolism of tobacco constituents.

The association of the MPO G-463A polymorphism by lung cancer histologic types has been conflicting, probably because of the small size of previous subgroup analyses. Nine published studies report information on histology, five of them with negative results, ${ }^{5,40-43}$ one with a more pronounced protective effect in squamous cell carcinoma, ${ }^{37}$ one with a more pronounced effect in adenocarcinoma, ${ }^{26}$ and two with a more pronounced effect in small cell carcinoma. ${ }^{36,44}$ In the present pooled analysis, the association between the MPO G-463A polymorphism and lung cancer did not vary significantly according to histologic type, with perhaps a more evident inverse association for carcinoma not otherwise specified.

Previous studies $8,35,36,39,45$ indicated an inverse association between MPO and lung cancer in men, whereas others did not confirm the result. ${ }^{26,41,43,46}$ Although we did not observe statistically significant differences with gender, the protective effect of the A allele seemed to be more pronounced in males than in females, after adjustment for several confounding factors. It has been indicated ${ }^{47}$ that the $A$ allele is associated with the creation of an estrogen receptor binding site and with higher inducible levels of MPO by estrogen. In vitro studies suggest that estrogens increase the MPO $A$ allele promoter activity by several fold; females carrying at least one MPO $A$ allele have been reported as having significantly higher levels of DNA adducts than those carrying the MPO $G / G$ genotype. ${ }^{48}$

Another published finding is that the MPO G-463A polymorphism may be more protective toward lung cancer in younger individuals, $8,35,36,39,45$ although other studies did not confirm this observation ${ }^{26,40,43,46}$ or reported the opposite..$^{38,44}$ MPO activity has been reported to be lower in women with the $-463 G A$ genotype who are aged less than 45 years than in those aged more than 55 years with the same genotype. ${ }^{49}$ The opposite effect, although not significant, was found in men. ${ }^{49} \mathrm{We}$ did not observe differences in the association according to age in the two genders. Most individual studies will not have large numbers of young subjects; therefore, the reported age modification effects are likely to be derived from the small sample size of previous studies.

\section{CONCLUSION}

The large dataset deriving from the GSEC study and the ability to adjust the data for confounding factors gave us the opportunity to contribute to the understanding of the role played by gender, age, and smoking habits in the association between MPO and lung cancer. It is possible that gender and age differences in lung cancer risk related to the MPO G-463A polymorphism actually reflect gender and age differences in length or duration of smoking, two cofactors that may not have always been controlled for in the analysis.

\section{References}

1. Klebanoff SJ. Myeloperoxidase: friend and foe. J Leukocyte Biol 2005;77(5):598625 .
2. Andrews PC, Krinsky NI. The reductive cleavage of myeloperoxidase in half, producing enzymically active hemi-myeloperoxidase. J Biol Chem 1981;256(9):42114218.

3. Johnson KR, Nauseef WM, Care A, Wheelock MJ, et al. Characterization of cDNA clones for human myeloperoxidase: predicted amino acid sequence and evidence for multiple mRNA species. Nucleic Acids Res 1987;15(5):2013-2028.

4. Arnljots K, Olsson I. Myeloperoxidase precursors incorporate heme. J Biol Chem 1987;262(22):10430-10433.

5. Chevrier I, Stucker I, Houllier AM, Cenee S, et al. Myeloperoxidase: new polymorphisms and relation with lung cancer risk. Pharmacogenetics 2003;13(12):729-739.

6. Pember SO, Fuhrer-Krusi SM, Barnes KC, Kinkade JM Jr., et al. Isolation of three native forms of myeloperoxidase from human polymorphonuclear leukocytes. FEBS Lett 1982;140(1):103-108.

7. Eiserich JP, Baldus S, Brennan ML, Ma W, et al. Myeloperoxidase, a leukocytederived vascular NO oxidase. Science 2002;296(5577):2391-2394.

8. Schabath MB, Spitz MR, Delclos GL, Gunn GB, et al. Association between asbestos exposure, cigarette smoking, myeloperoxidase (MPO) genotypes, and lung cancer risk. Am J Ind Med 2002;42(1):29-37.

9. Spickett CM, Jerlich A, Panasenko OM, Arnhold J, et al. The reactions of hypochlorous acid, the reactive oxygen species produced by myeloperoxidase, with lipids. Acta Biochim Pol 2000;47(4):889-899.

10. Vile GF, Rothwell LA, Kettle AJ. Hypochlorous acid activates the tumor suppressor protein p53 in cultured human skin fibroblasts. Arch Biochem Biophys 1998;359(1): 51-56.

11. Vile GF, Rothwell LA, Kettle AJ. Initiation of rapid, P53-dependent growth arrest in cultured human skin fibroblasts by reactive chlorine species. Arch Biochem Biophys 2000;377(1):122-128.

12. Klebanoff SJ. Myeloperoxidase. Proc Assoc Am Physicians 1999;111(5):383-389.

13. Kiyohara C, Otsu A, Shirakawa T, Fukuda S, et al. Genetic polymorphisms and lung cancer susceptibility: a review. Lung Cancer 2002;37(3):241-256.

14. Whiteman M, Spencer JP, Jenner A, Halliwell B, et al. Hypochlorous acid-induced DNA base modification: potentiation by nitrite: biomarkers of DNA damage by reactive oxygen species. Biochem Biophys Res Commun 1999;257(2):572-576.

15. Masuda M, Suzuki T, Friesen MD, Ravanat JL, et al. Chlorination of guanosine and other nucleosides by hypochlorous acid and myeloperoxidase of activated human neutrophils. Catalysis by nicotine and trimethylamine. J Biol Chem 2001;276(44): 40486-40496.

16. Nauseef WM, Brigham S, Cogley M. Hereditary myeloperoxidase deficiency due to a missense mutation of arginine 569 to tryptophan. J Biol Chem 1994;269:12121216.

17. Kizaki M, Miller CW, Selsted ME, Koeffler HP, et al. Myeloperoxidase (MPO) gene mutation in hereditary MPO deficiency. Blood 1994;83:1935-1940.

18. Nauseef W, Cogley M, McCormick S. Effect of the R569W missense mutation on the biosynthesis of myeloperoxidase. J Biol Chem 1996;271:9546-9549.

19. DeLeo FR, Goedken M, McCormick SJ, Nauseef WM, et al. A novel form of hereditary myeloperoxidase deficiency linked to endoplasmic reticulum/ proteasome degradation. J Clin Invest 1998;101:2900-2909.

20. Romano M, Dri P, Dadalt L, Patriarca P, et al. Biochemical and molecular characterization of hereditary myeloproliferative deficiency. Blood 1997;90:4126-4134.

21. Piedrafita FJ, Molander RB, Vansant G, Orlova EA, et al. An Alu element in the myeloperoxidase promoter contains a composite SP1-thyroid hormone-retinoic acid response element. J Biol Chem 1996;271(24):14412-14420.

22. Vansant G, Reynolds WF. The consensus sequence of a major Alu subfamily contains a functional retinoic acid response element. Proc Natl Acad Sci U S A 1995; 92(18):8229-8233.

23. Van Schooten FJ, Boots AW, Knaapen AM, Godschalk RWL, et al. Myeloperoxidase (MPO) $-463 G-A$ reduced MPO activity and DNA adduct levels in bronchoalveolar lavages of smokers. Cancer Epidemiol Biomarkers Prev 2004;13(5):828-833.

24. Reynolds WF, Chang E, Douer D, Ball ED, et al. An allelic association implicates myeloperoxidase in the etiology of acute promyelocytic leukaemia. Blood 1997;90: 2730-2737.

25. Nikpoor B, Turecki G, Fournier C, Theroux P, et al. A functional myeloperoxidase polymorphic variant is associated with coronary artery disease in French-Canadians. Am Heart J 2001;142(2):336-339.

26. Cascorbi I, Henning S, Brockmoller J, Gephart J, et al. Substantially reduced risk of cancer of the aerodigestive tract in subjects with variant-463A of the myeloperoxidase gene. Cancer Res 2000;60(3):644-649.

27. Nagra RM, Becher B, Tourtellotte WW, Antel JP, et al. Immunohistochemical and genetic evidence of myeloperoxidase involvement in multiple sclerosis. J Neuroimmunol 1997;78:97-107.

28. Reynolds WF, Rhees J, Maciejewski D, Paladino T, et al. Myeloperoxidase polymorphism is associated with gender specific risk for Alzheimer's disease. Exp Neurol 1999;155:31-41. 
29. Meisel P, Krause T, Cascorbi I, Schroeder W, et al. Gender and smoking-related risk reduction of periodontal disease with variant myeloperoxidase alleles. Genes Immun 2002;3(2):102-106.

30. Kiyohara C, Yoshimasu K, Takayama K, Nakanishi Y, et al. NQO1, MPO, and the risk of lung cancer: a HuGE review. Genet Med 2005;7(7):463-478.

31. Taioli E. International collaborative study on genetic susceptibility to environmental carcinogens. Cancer Epidemiol Biomarkers Prev 1999;8(8):727-728.

32. Thakkinstian A, McElduff P, D'Este C, Duffy D, et al. A method for meta-analysis of molecular association studies. Stat Med 2005;24(9):1291-1306.

33. Egger D, Smith M, Schneider C. Minder. Bias in meta-analysis detected by a simple, graphical test. BMJ 1997;315:629-634.

34. DerSimonian R, Laird N. Meta-analysis in clinical trials. Control Clin Trials 1986 7(3):177-188.

35. Schabath MB, Spitz MR, Zhang X, Delclos GL, et al. Genetic variants of myeloper oxidase and lung cancer risk. Carcinogenesis 2000;21(6):1163-1166.

36. Schabath MB, Spitz MR, Hong WK, Delclos GL, et al. A myeloperoxidase polymorphism associated with reduced risk of lung cancer. Lung Cancer 2002;37:35-40.

37. Lu W, Xing D, Qi J, Tan W, et al. Genetic polymorphism in myeloperoxidase but no GSTM1 is associated with risk of lung squamous cell carcinoma in a Chinese population. Int J Cancer 2002;102(3):275-279.

38. Dally H, Gassner K, Jager B, Schmezer P, et al. Myeloperoxidase (MPO) genotype and lung cancer histologic types: the MPO $-463 \mathrm{~A}$ allele is associated with reduced risk for small cell lung cancer in smokers. Int J Cancer 2002;102(5):530-535.

39. Skuladottir H, Autrup H, Autrup J, Tjoenneland A, et al. Polymorphisms in genes involved in xenobiotic metabolism and lung cancer risk under the age of 60 years. A pooled study of lung cancer patients in Denmark and Norway. Lung Cancer 2005;48(2):187-199.

40. London SJ, Lehman TA, Taylor JA, et al. Myeloperoxidase genetic polymorphism and lung cancer risk. Cancer Res 1997;57:5001-5003.

41. Le Marchand L, Seifried, Lum A, Wilkens LR. Association of the myeloperoxidase $-463 \mathrm{G} \rightarrow$ A polymorphism with lung cancer risk. Cancer Epidemiol Biomarkers Prev 2000;9:181-184.

42. Liu G, Zhou W, Wang LI, Park S, et al. MPO and SOD2 polymorphisms, gender, and the risk of non-small cell lung carcinoma. Cancer Lett 2004;214(1):69-79.
43. Xu LL, Liu G, Miller DP, Zhou W, et al. Counterpoint: the myeloperoxidase $-463 G \rightarrow A$ polymorphism does not decrease lung cancer susceptibility in Caucasians. Cancer Epidemiol Biomarkers Prev 2002;11:1555-1559.

44. Dally H, Bartsch H, Risch A. Counterpoint: the myeloperoxidase $(-463) \mathrm{G}->$ a polymorphism does not decrease lung cancer susceptibility in Caucasians. Cancer Epidemiol Biomarkers Prev 2003;12(7):683.

45. Misra RR, Tangrea JA, Virtamo J, Ratnasinghe D, et al. Variation in the promoter region of the myeloperoxidase gene is not directly related to lung cancer risk among male smokers in Finland. Cancer Lett 2001;164(2):161-167.

46. Cajas-Salazar N, Sierra-Torres CH, Salama SA, Zwischenberger JB, et al. Combined effect of MPO, GSTM1 and GSTT1 polymorphisms on chromosome aberrations and lung cancer risk. Int J Hyg Environ Health 2003;206(6):473-483.

47. Reynolds WNF, Hiltunen M, Pirskanen M, Mannermaa A, et al. MPO and APOEepsilon4 polymorphisms interact to increase risk for AD in Finnish males. Neurology 2000;55:1284-1290.

48. Brockstedt U, Krajinovic M, Richer C, Mathonnet G, et al. Analyses of bulky DNA adduct levels in human breast tissue and genetic polymorphisms of cytochromes P450 (CYPs), myeloperoxidase (MPO), quinone oxidoreductase (NQO1), and glutathione S-transferases (GSTs). Mutat Res 2002;516:41-47.

49. Rutgers A, Heeringa P, Giesen JEHM, Theunissen RT, et al. Neutrophil myeloperoxidase activity and the influence of two single-nucleotide promoter polymorphisms. Br J Haematol 2003;123:536-538.

50. Feyer A, Voho A, Bouchardy C, Kuokkanen K, et al. Myeloperoxidase $-463 G \rightarrow A$ polymorphism and lung cancer risk. Cancer Epidemiol Biomarkers Prev 2002;11: 1550-1554.

51. Kantaraci OH, Lesnick TG, Yang P, Meyer RL, et al. Myeloperoxidase $-463(G \rightarrow A)$ polymorphism associated with lower risk of lung cancer. Mayo Clin Proc 2002;77: $17-22$.

52. Larsen EJ, Colosimo ML, Yang IA, Bowman R, et al. CYP1A1 Ile462Val and MPO G-463A interact to increase risk of adenocarcinoma but not squamous cell carcinoma of the lung. Carcinogenesis 2006;27:525-532.

53. Blettner M, Sauerbrei W, Schlehofer B, et al. Traditional reviews, meta-analyses and pooled analyses in epidemiology. Int J Epidemiol 1999;28:1-9. 